(C) 2002 American Chemical Society, J. Org. Chem., Torres jo011174h Supporting Info Page 1

怘
品
这

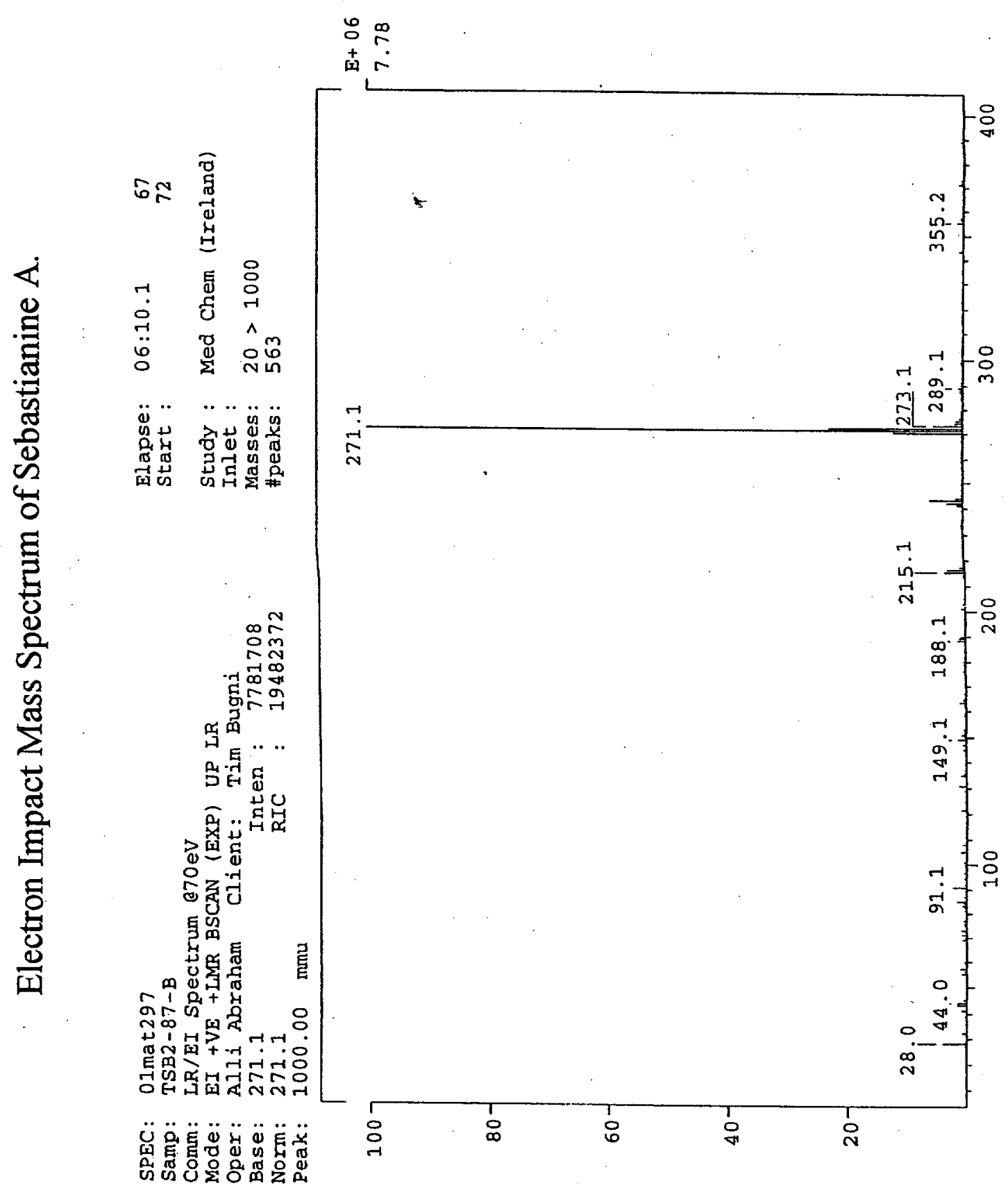


(C) 2002 American Chemical Society, J. Org. Chem., Torres jo011174h Supporting Info Page 2
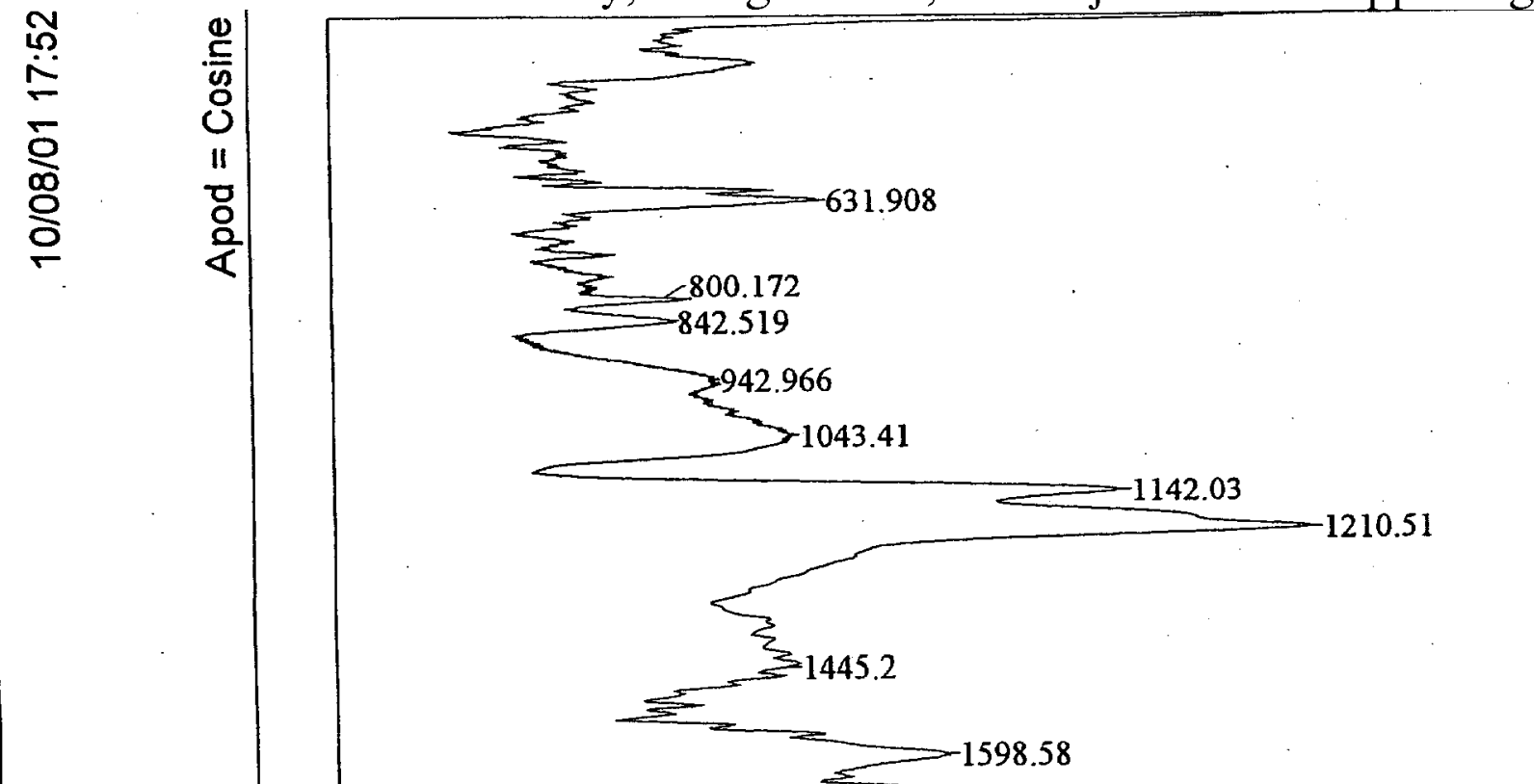

-8요

$\checkmark$

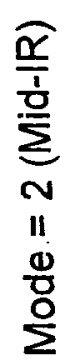

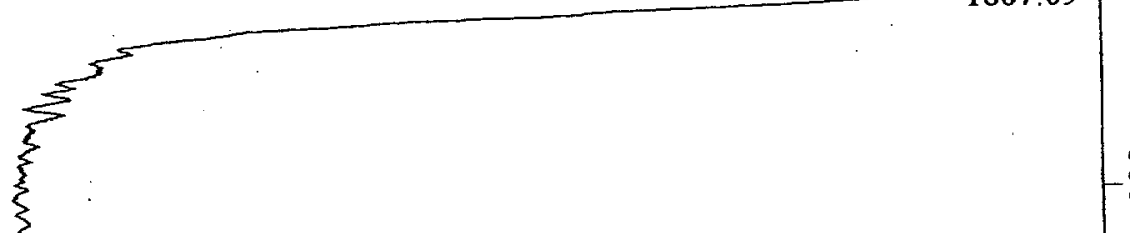

웅

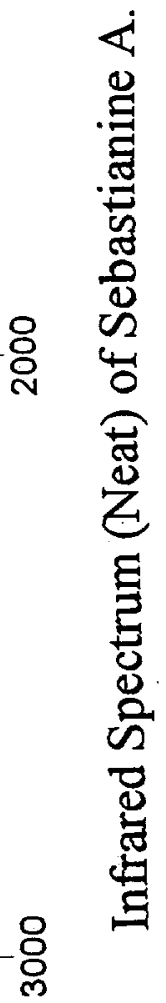

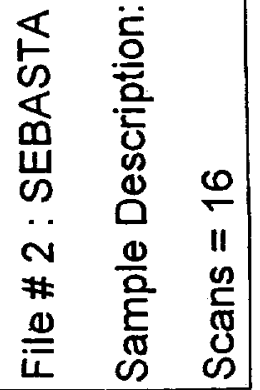




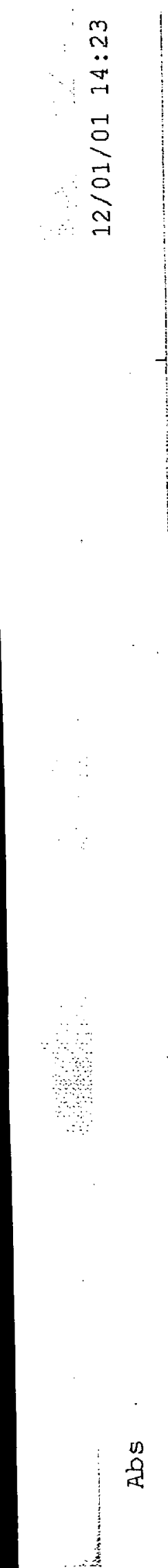

$m$
$y$
$\ddot{1}$
-1
0
0
-1
0
0

0

용

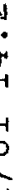

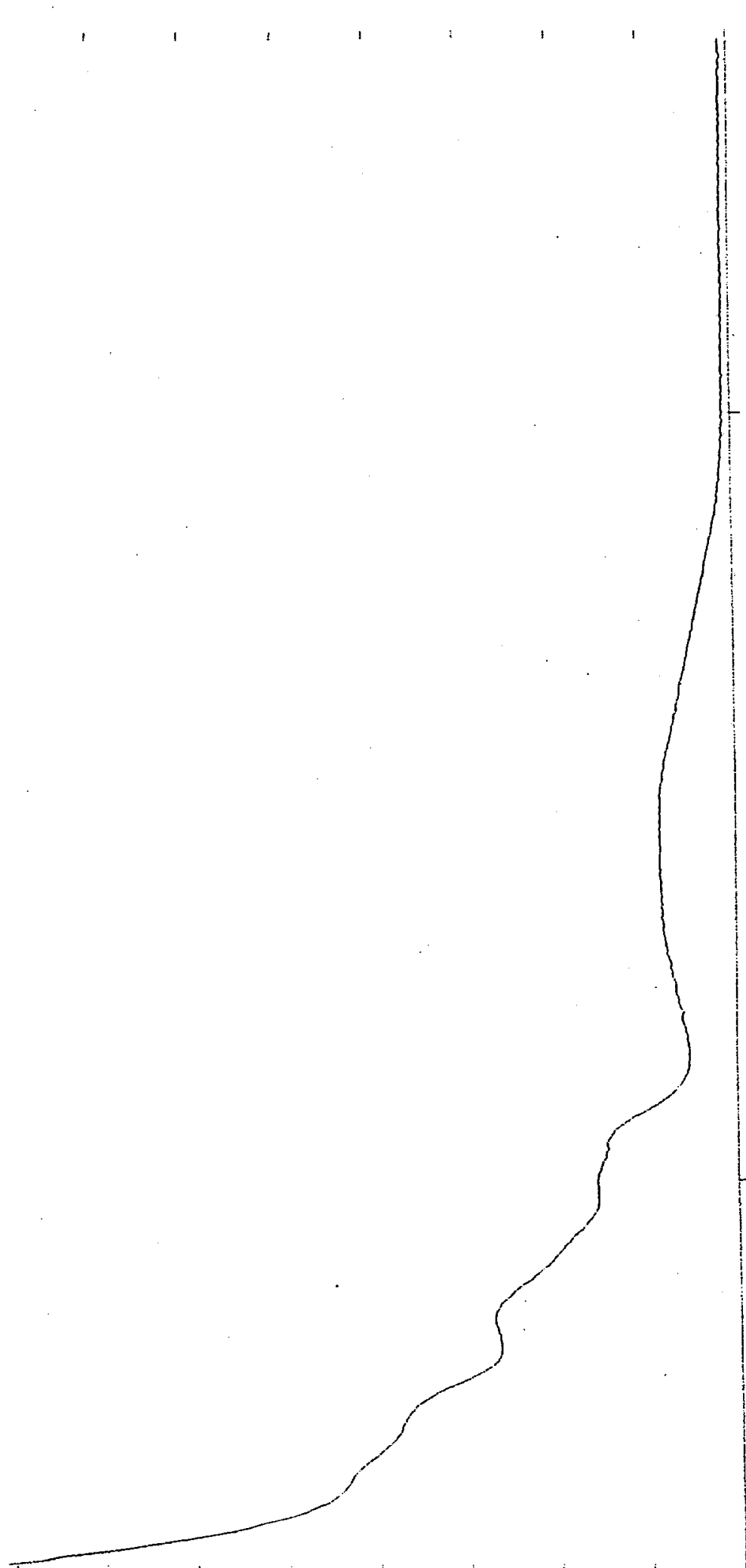

8
8
8
8
8


0
8
8
8

$\circ$
$\circ$
$\circ$

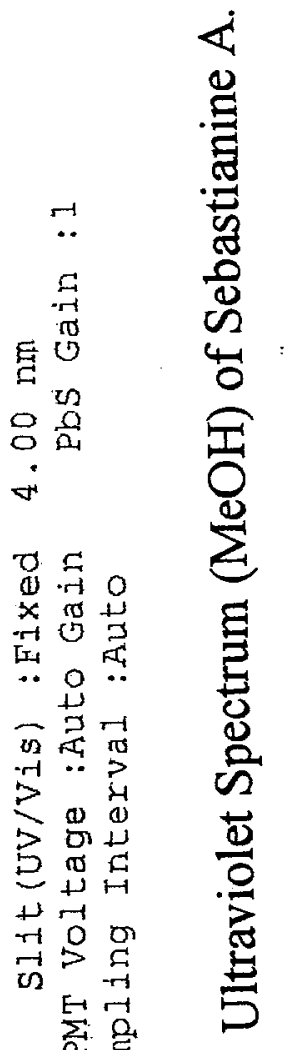

0

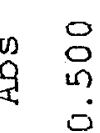

$:$
0
0
0
0

0

$\begin{array}{ll}0 & 0 \\ \text { m } & \text { m }\end{array}$

in

8

in

0

0

¿ 
(C) 2002 American Chemical Society, J. Org. Chem., Torres jo011174h Supporting Info Page 4
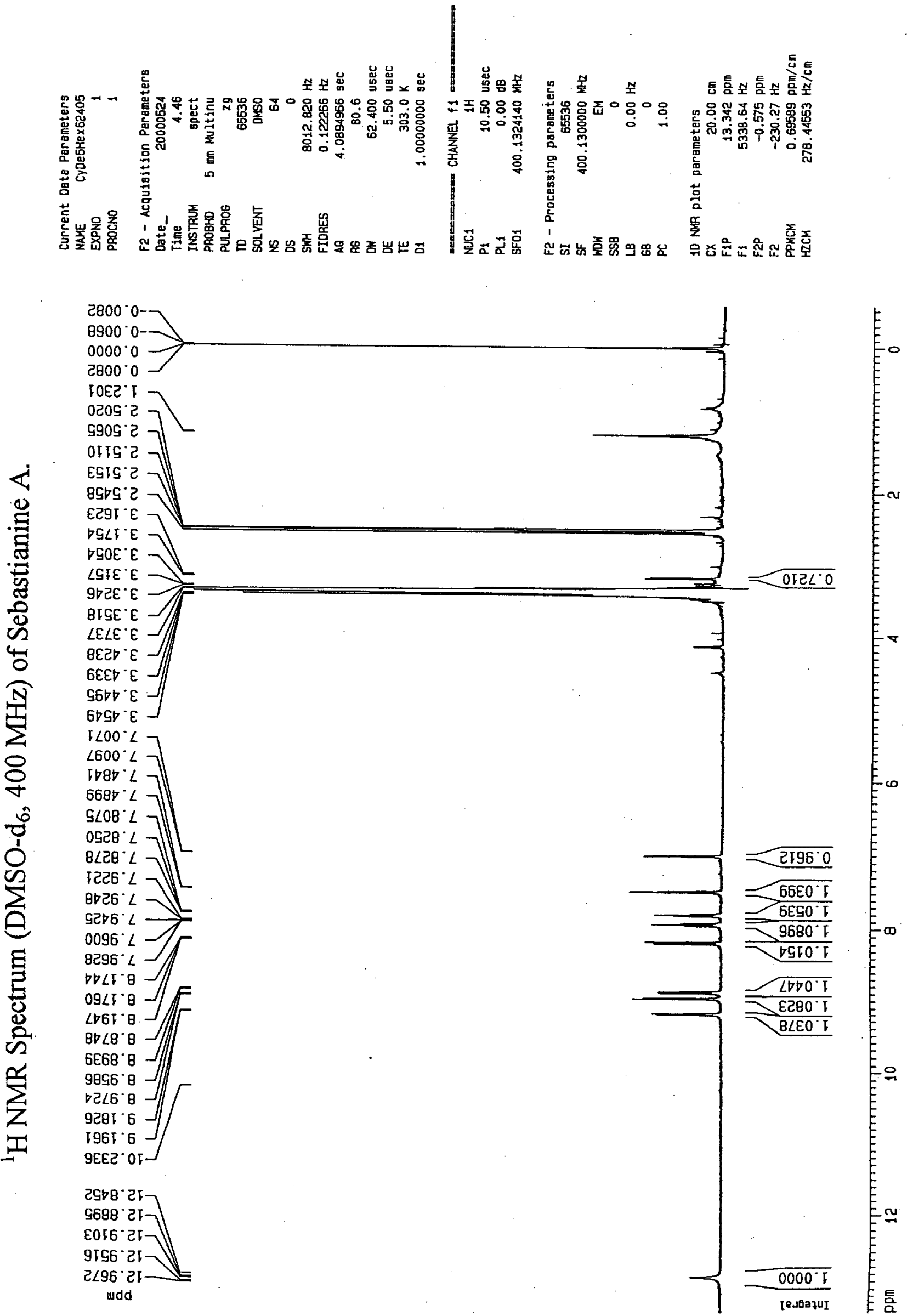
(C) 2002 American Chemical Society, J. Org. Chem., Torres jo011174h Supporting Info Page 5

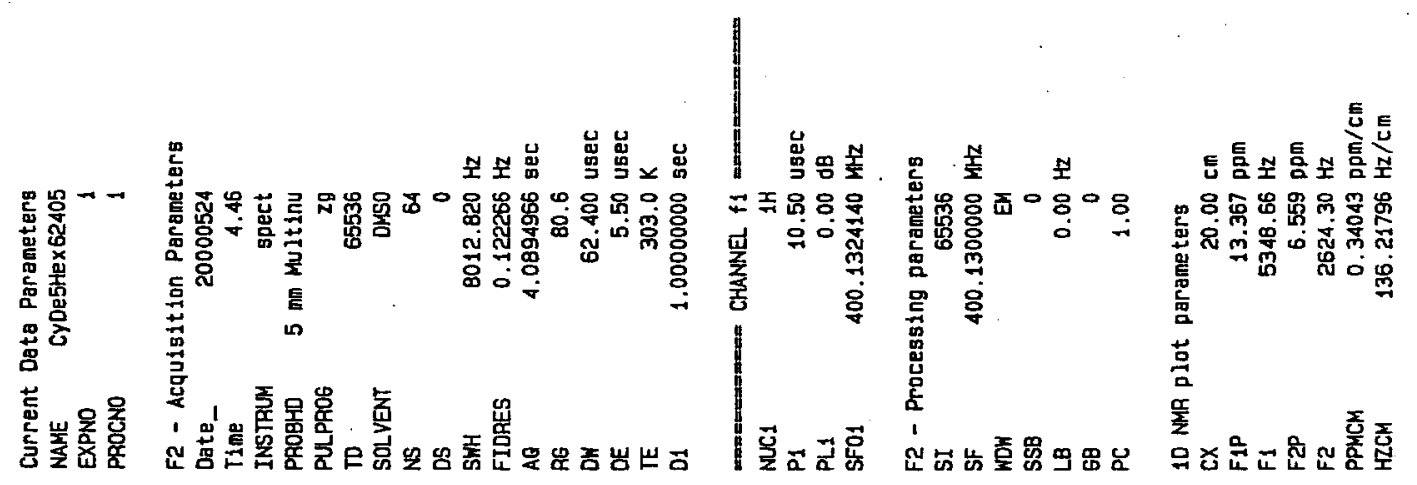

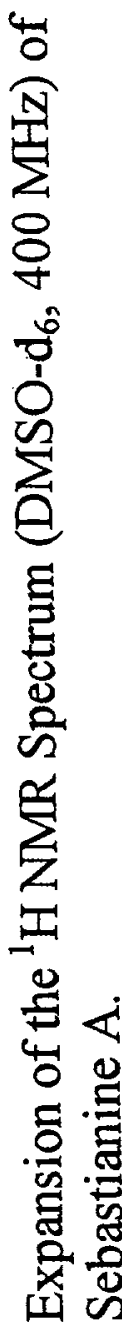

$8600^{\circ}$

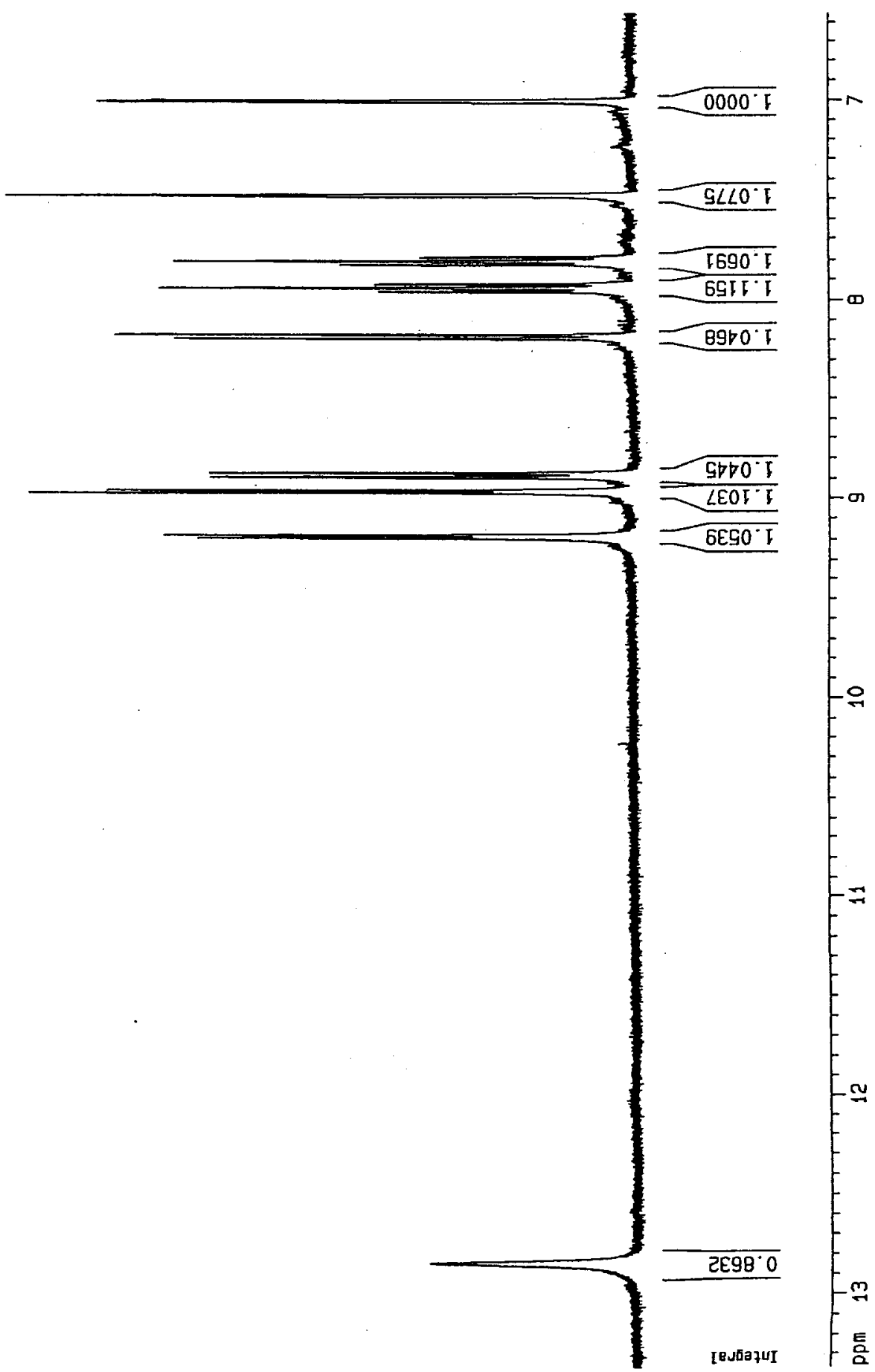


(C) 2002 American Chemical Society, J. Org. Chem., Torres jo011174h Supporting Info Page 6
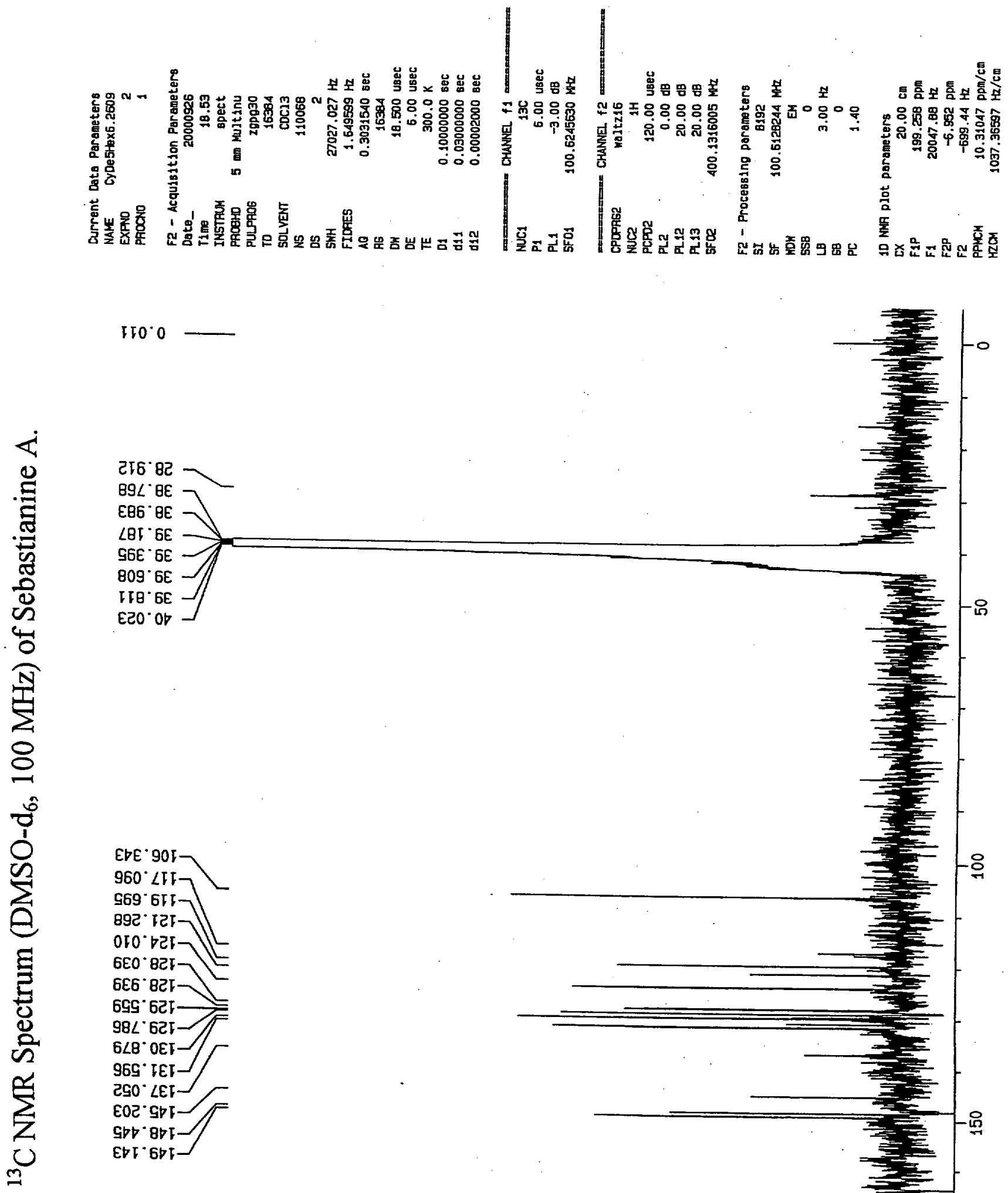

$6266^{\circ} \mathrm{KL}$ 
(C) 2002 American Chemical Society, J. Org. Chem., Torres jo011174h Supporting Info Page 7

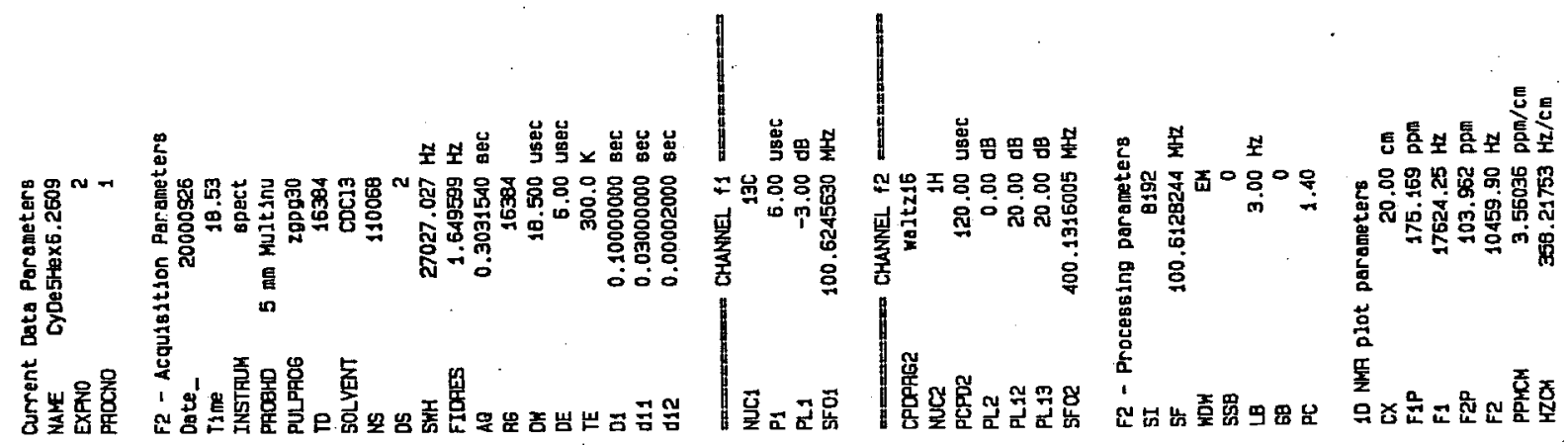

EtE. $90 \mathrm{r}$

$960^{\circ} \angle I L$

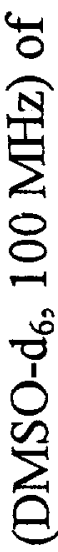

$969.657-2$

892 เ

OLO'DCF -

$6 E 0^{\circ} \mathrm{BC}$

6E6. $\mathrm{BCI}$

$699^{\circ} 625$

$98 L^{\circ} 625$

$6 \angle 8^{\circ} 0 E 5$

$969^{\circ} \mathrm{IEF}-$

$250^{\circ} \angle E F \longrightarrow$

$\varepsilon 0 e^{\prime} 55$

S40.851-

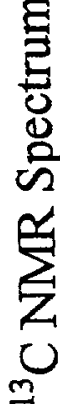

EbF.6bI-

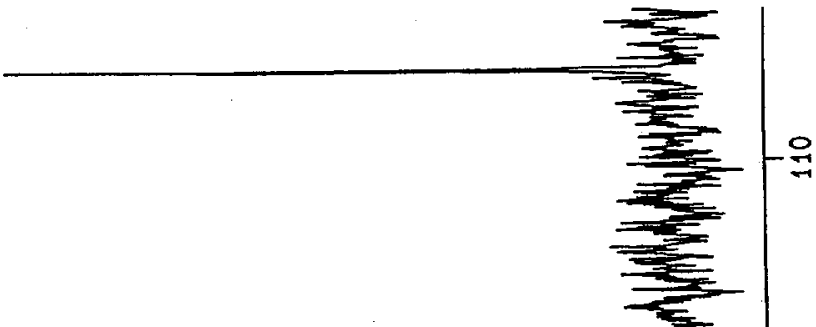

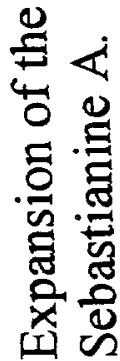

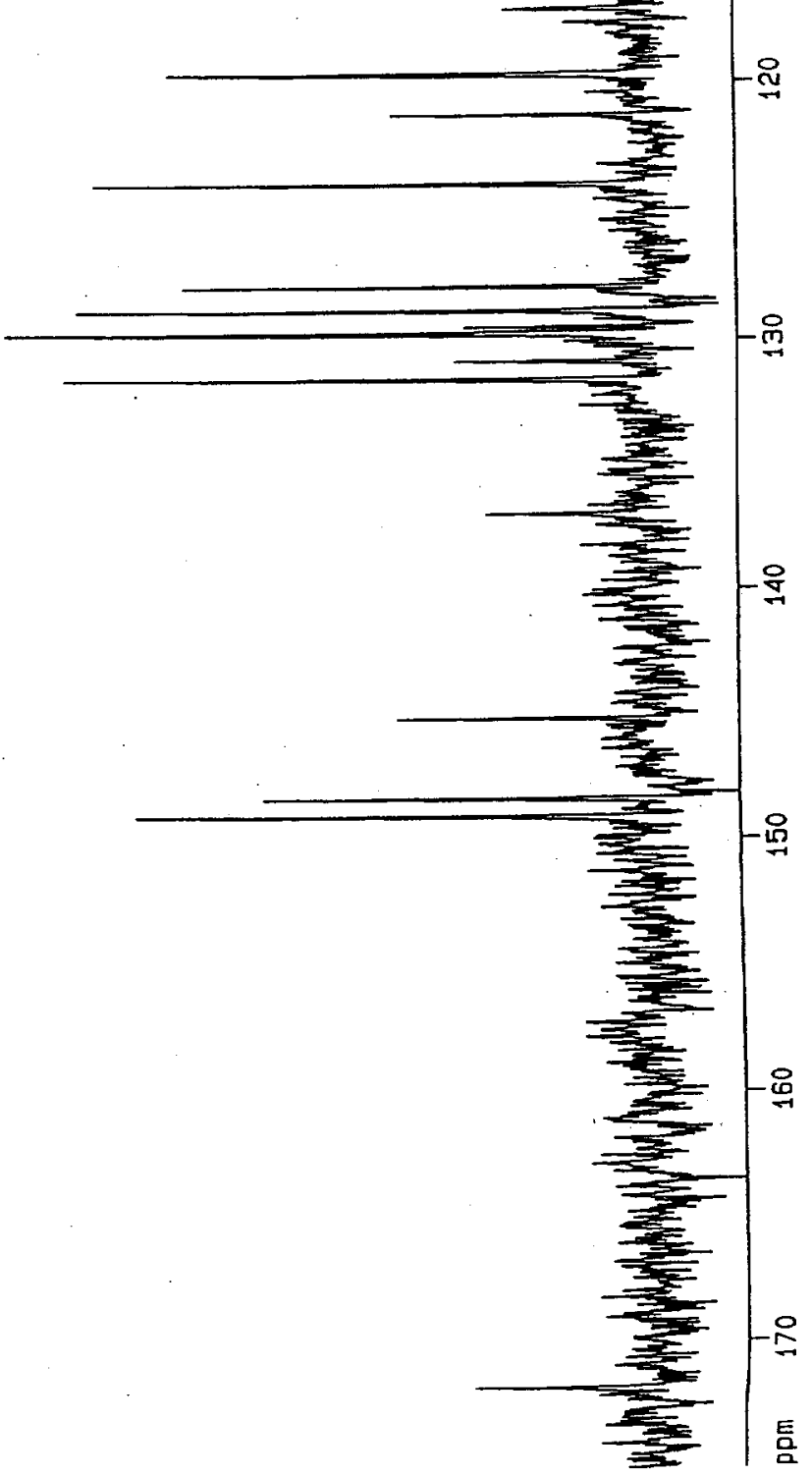


(C) 2002 American Chemical Society, J. Org. Chem., Torres jo011174h Supporting Info Page 8,

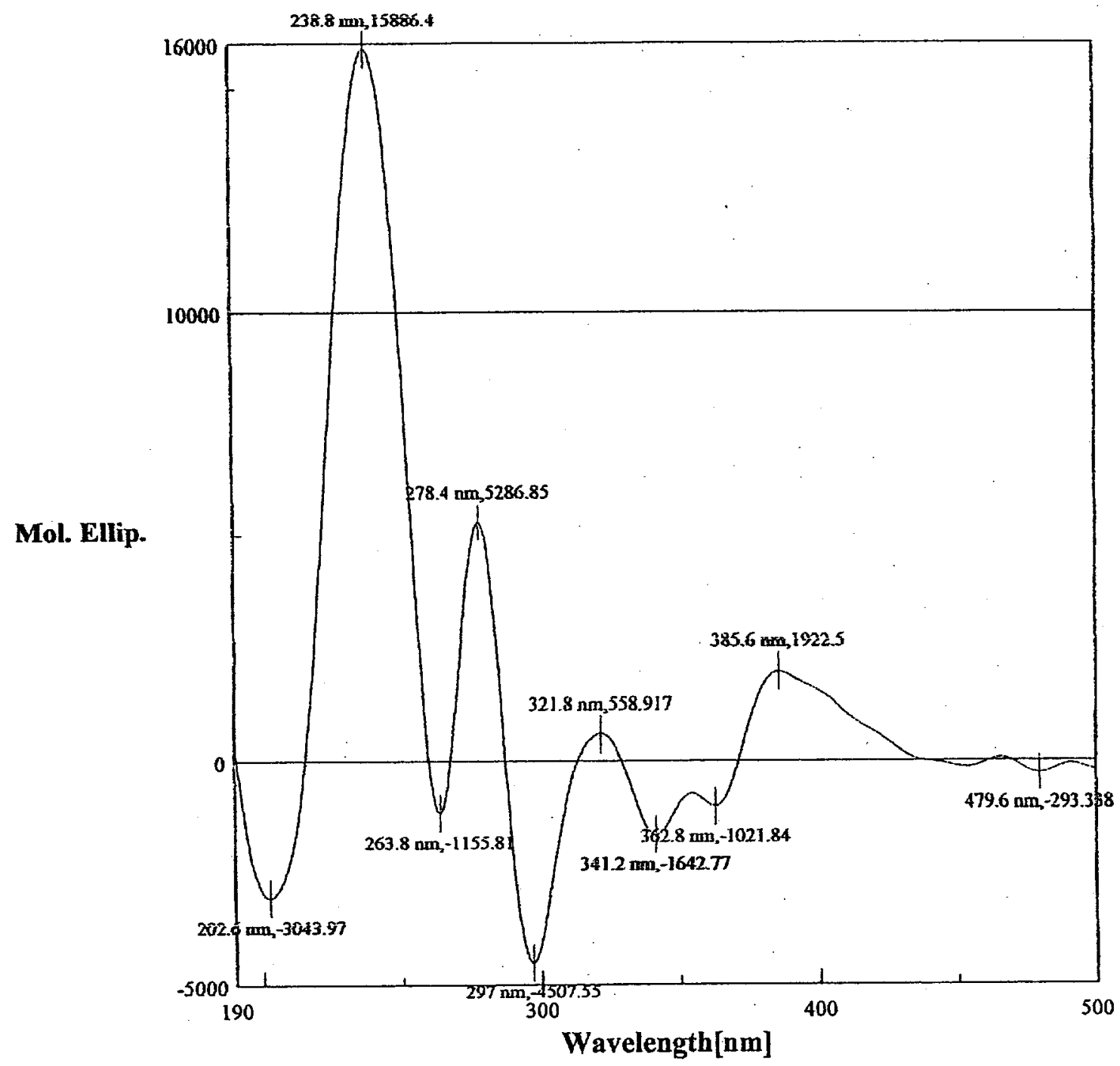

tsb2-87-c

Filename: $\quad$ a7c_malp.jws

Sample: $\quad$ tsb2-87-c

Cell Length : $\quad 1 \mathrm{~cm}$

Concentration : $\quad 0.000107 \mathrm{M}$

Solvent: $\mathrm{MeOH}$

Temperature: $\quad 25 \mathrm{C}$

Operator: $\quad$ Tim Bugni

Organization: Medicinal Chemistry

Comment :

Data mode :

Ch2-mode:

Range:<smiles>CC(C)[C@H]1O[C@@]2(O)C3=C(CCN3C1=O)c1nc3ccccc3c3ccnc2c13</smiles>

(2)

Sensitivity: $\quad 50$ mdeg

Resalution : $\quad 0.2 \mathrm{~nm}$

Accumulation : 1

1,0 nm

Response: $\quad 0.25 \mathrm{sec}$

Speed : $\quad 50$ nmimin 
(c) 2002 American Chemical Society, J. Org. Chem., Torres jo011174h Supporting Info Page 9 ,

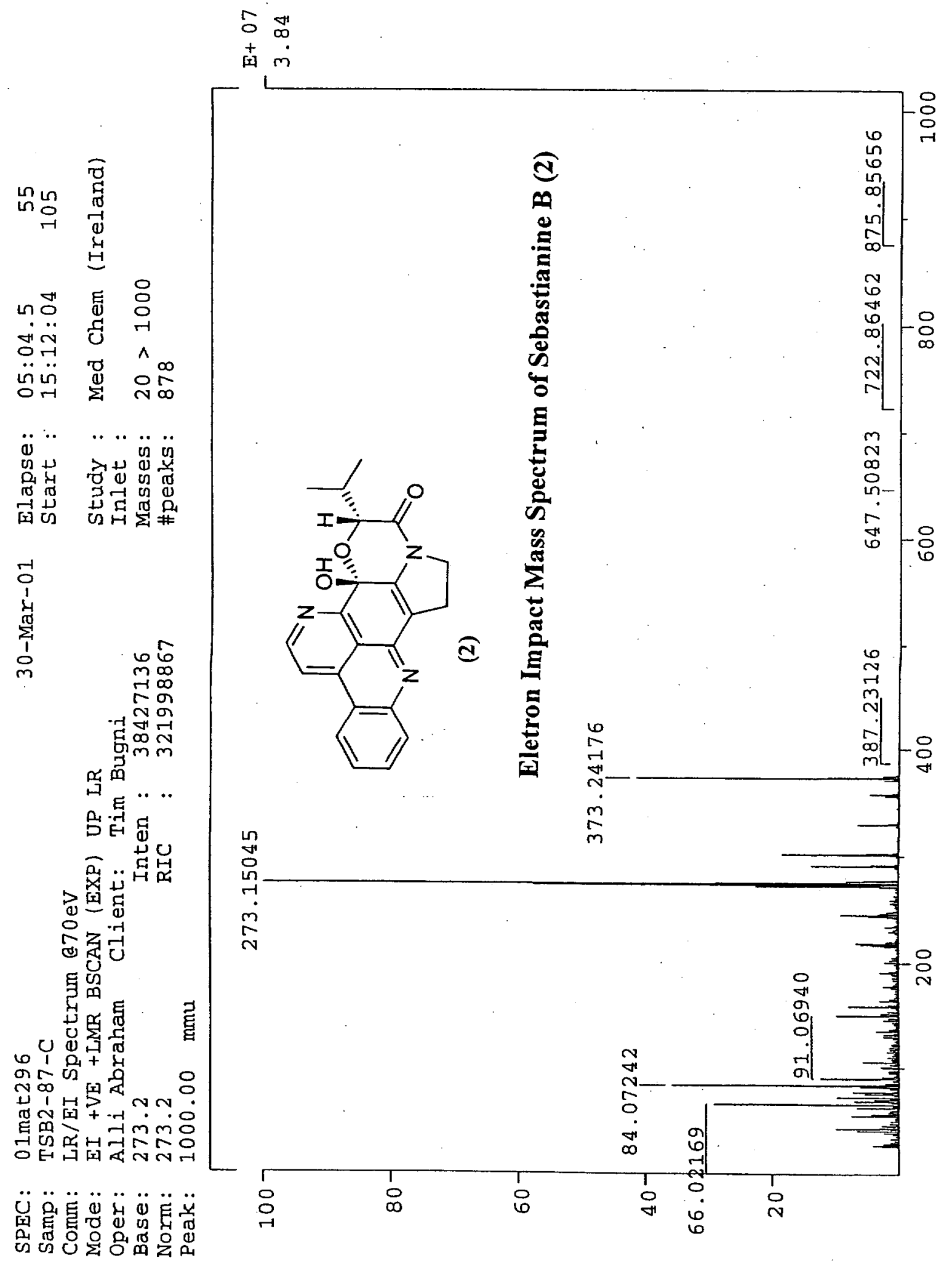


(C) 2002 American Chemical Society, J. Org. Chem., Torres jo011174h Supporting Info Page 10

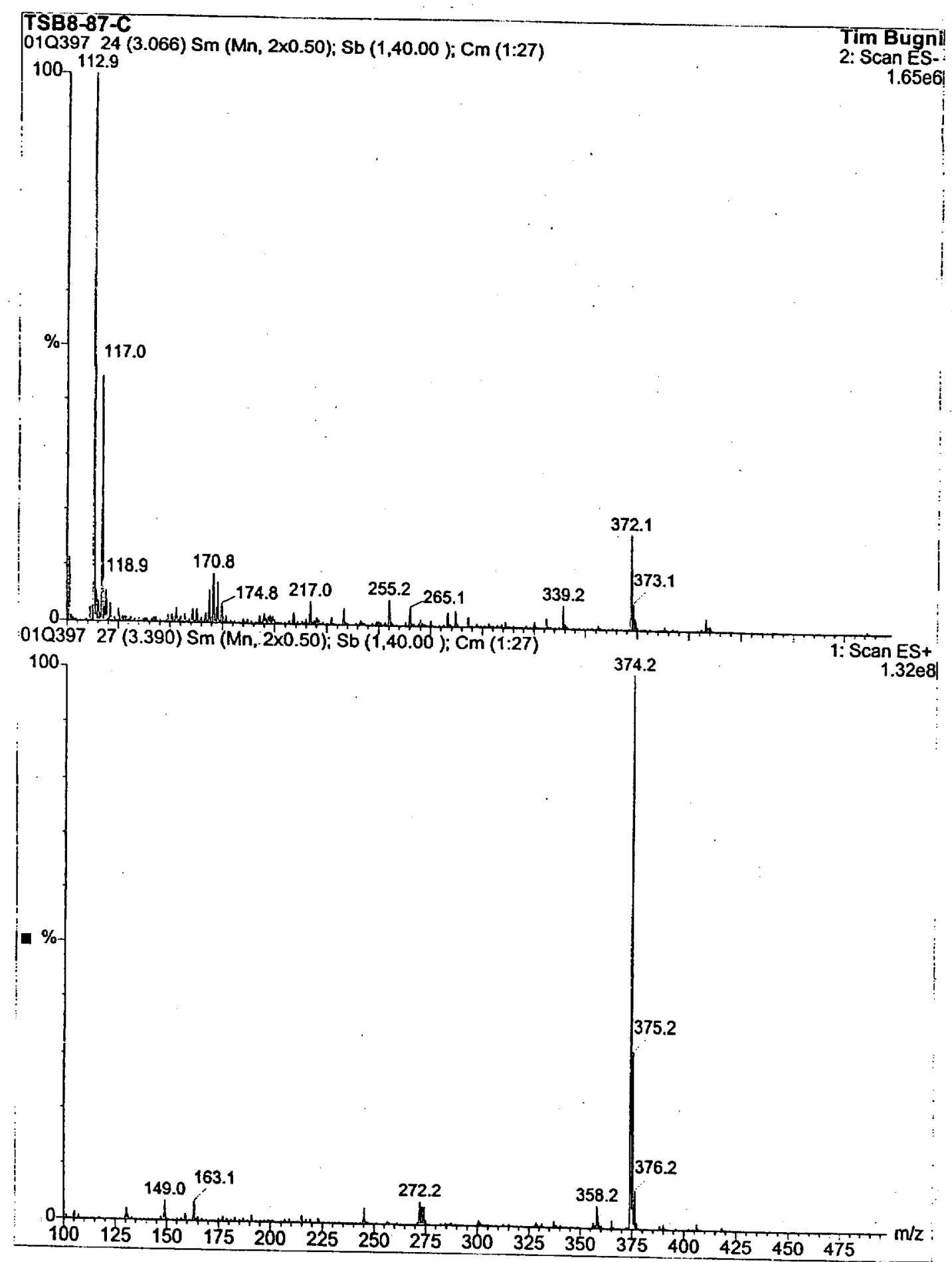<smiles>CC(C)[C@H]1O[C@@]2(O)C3=C(CCN3C1=O)c1nc3ccccc3c3ccnc2c13</smiles> 
(C) 2002 American Chemical Society, J. Org. Chem., Torres jo011174h Supporting Info Page 11 v)

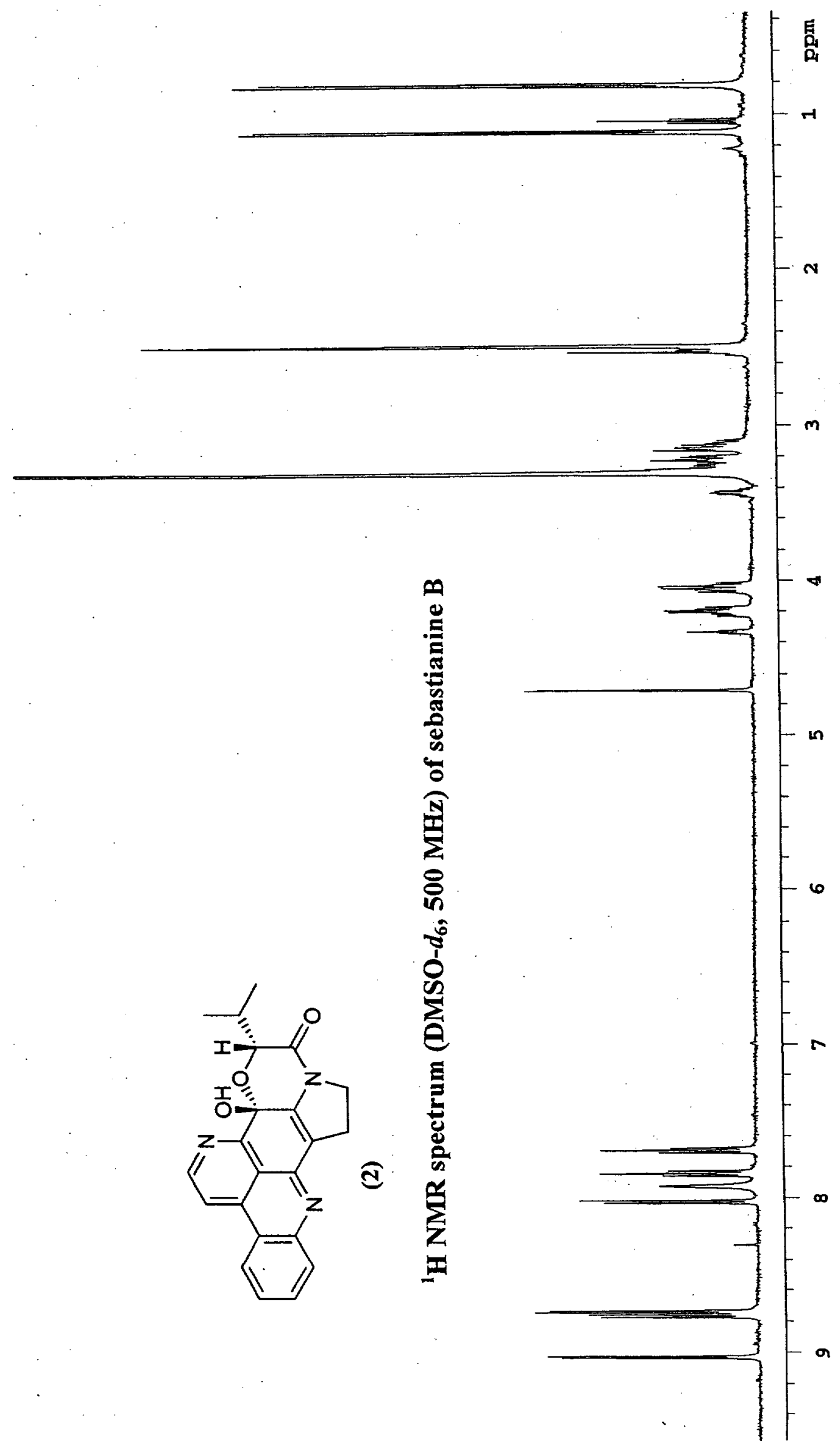


(C) 2002 American Chemical Society, J. Org. Chem., Torres jo011174h Supporting Info Page 12 j)

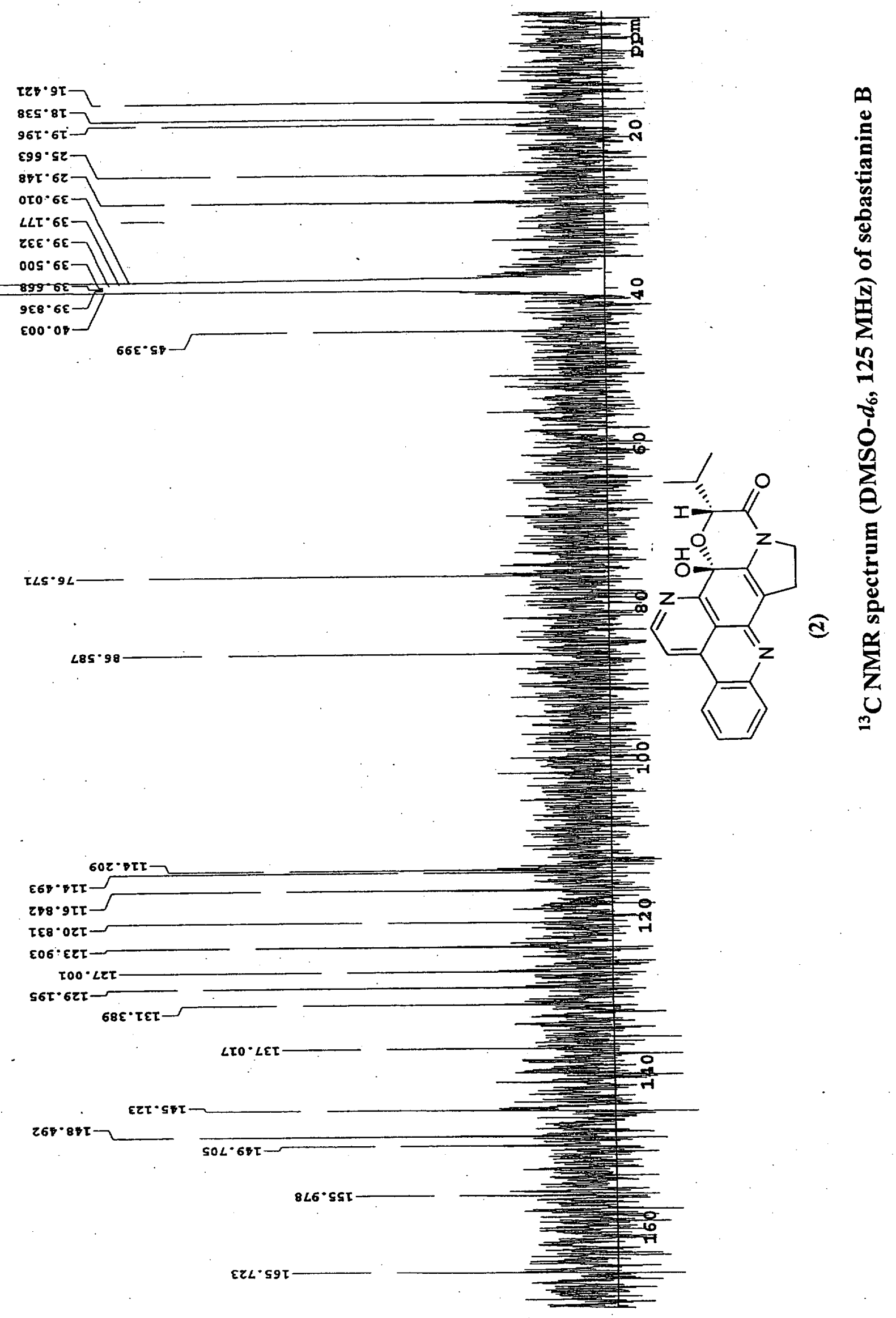


(ㄷ) 2002 American Chemical Society, J. Org. Chem., Torres jo011174h Supporting Info Page 13

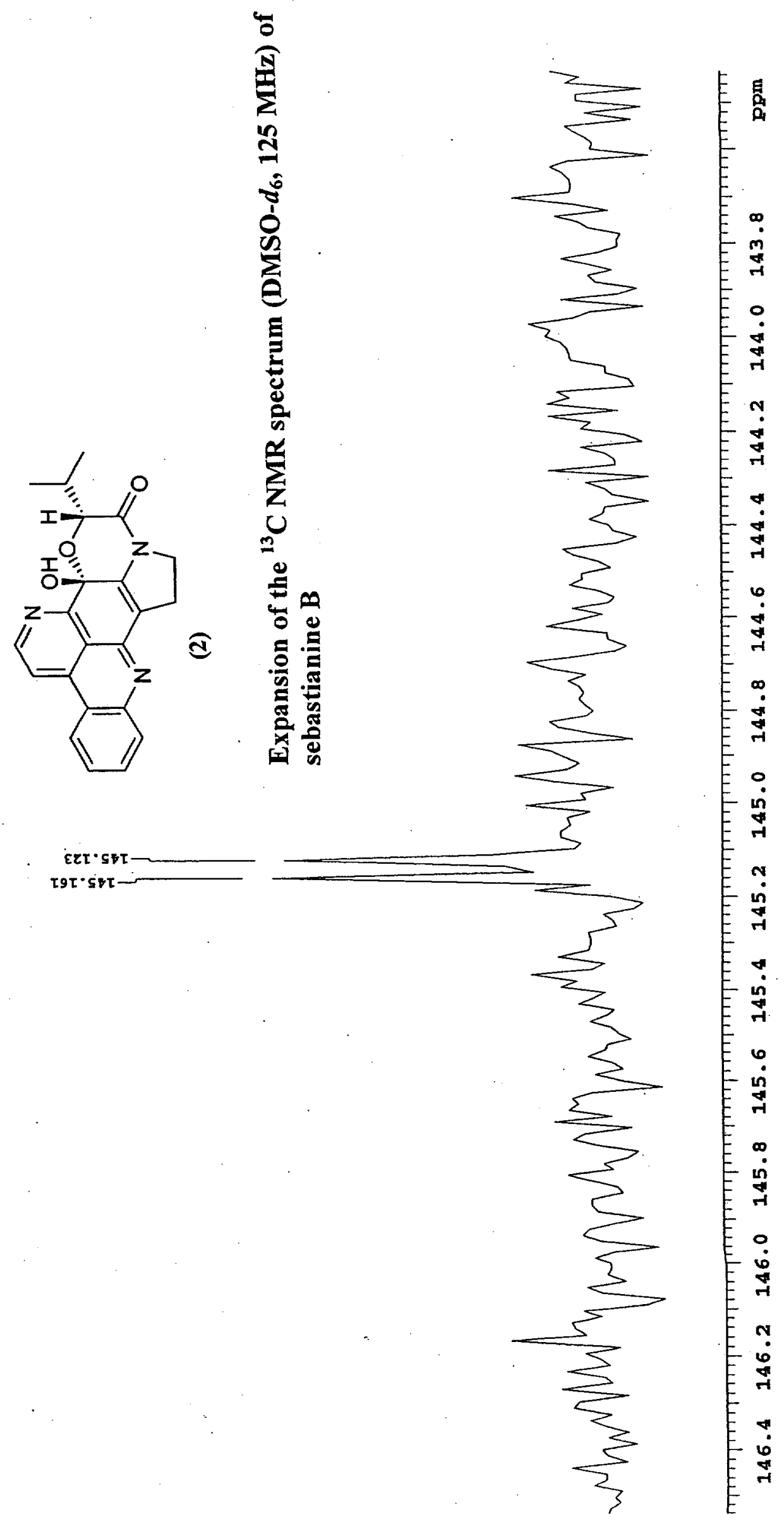




\section{ChemNMR C-13 Estimation}

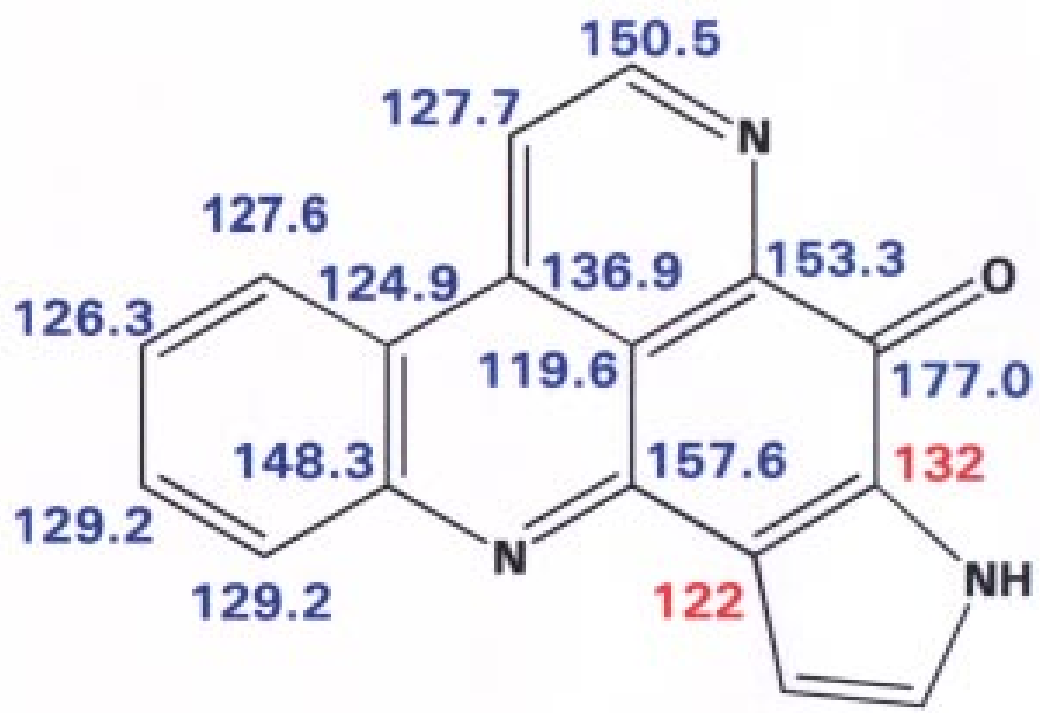

(1)

111

127

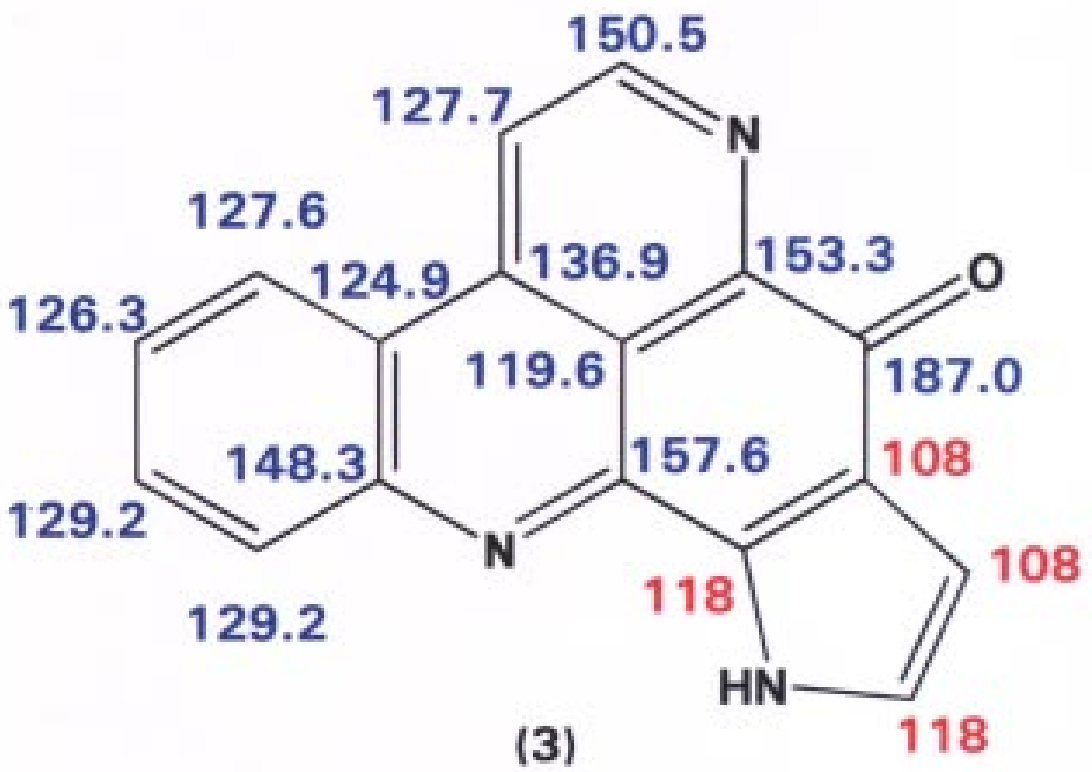

Estimation Quality: blue $=$ good, magenta $=$ medium, red $=$ rough 